\title{
STABILITY INDICATING RP-HPLC ASSAY OF HYDROCODONE AND IBUPROFEN IN TABLETS
}

\author{
RAMA KUMAR KANDULA ${ }^{*}$, RAJA SUNDARARAJAN ${ }^{1}$
}

1Institute of Pharmacy, GITAM University, Visakhapatnam, Andhra Pradesh, India 530045

Email: ramakumarkandula@gmail.com

Received: 02 Apr 2019, Revised and Accepted: 24 May 2019

\section{ABSTRACT}

Objective: The combination of hydrocodone and ibuprofen is prescribed to temporarily relieve severe pain. A new selective, precise and accurate stability indicating reverse-phase high-performance liquid chromatography (RP-HPLC) technique was developed for identification and estimation of hydrocodone and ibuprofen in tablets.

Methods: The analysis of hydrocodone and ibuprofen was executed on phase Zodiac C18 (250 × $4.6 \mathrm{~mm}$, $5 \mathrm{~m})$ column with sodium dihydrogen phosphate $(0.1 \mathrm{M}, \mathrm{pH} 5.0)$ and methanol $(60: 40, v: v)$ as a mobile phase with a flow rate of $1.0 \mathrm{ml} / \mathrm{min}$. The detection and measurement were done at $234 \mathrm{~nm}$. The stability of hydrocodone and ibuprofen was examined under different conditions recommended by ICH, including alkaline, acidic, neutral, oxidative, photolytic and thermal.

Results: Hydrocodone and ibuprofen are eluted at $4.019 \mathrm{~min}$ and $4.999 \mathrm{~min}$, respectively. The assay method was linear (range: $3.75-11.25$ $\mu \mathrm{g} / \mathrm{ml}$ and $100-300 \mu \mathrm{g} / \mathrm{ml}$ ) with $R^{2}$ values of 0.9996 and 0.9999 for hydrocodone and ibuprofen, respectively. Method was accurate (recovery: $99.65 \%$ and $99.37 \%$ for hydrocodone and ibuprofen, respectively), precise (RSD: $0.262 \%$ and $0.261 \%$ for hydrocodone and ibuprofen, respectively), selective and robust. In degradation studies, peaks of degradants did not interfere with the peaks of hydrocodone and ibuprofen. This validated method was applied to assay the content of hydrocodone and ibuprofen in tablets.

Conclusion: This method can be opted in the routine quality control test of fixed-dose tablet combination comprising of hydrocodone and ibuprofen.

Keywords: Hydrocodone, Ibuprofen, Combination dosage form, Stress study, Analysis

(C) 2019 The Authors. Published by Innovare Academic Sciences Pvt Ltd. This is an open access article under the CC BY license (http://creativecommons.org/licenses/by/4.0/) DOI: http://dx.doi.org/10.22159/ijap.2019v11i4.33376

\section{INTRODUCTION}

Hydrocodone, chemically known as (4R,4aR,7aR,12bS)-9-methoxy3-methyl-1,2,4,4a,5,6,7a,13-octahydro-4,12-methanobenzofuro[3,2e]isoquinolin-7-one (fig. 1), is a derivative of the baine or codeine with antitussive and analgesic effects [1-3]. As an antitussive agent, hydrocodone is used to relieve nonproductive cough symptoms. As an analgesic agent, it is used to relieve moderate or severe pain. In the central nervous system, hydrocodone activates primarily the $\mu$ opioid3 receptor which results in analgesia, respiratory depression, euphoria, physical dependence and cough suppression $[4,5]$.

Ibuprofen, chemically known as 2-[4-(2-methylpropyl) phenyl] propanoic acid (fig. 1), is a derivative of propionic acid belonging to the nonsteroidal anti-inflammatory class of drugs [6-8]. Ibuprofen has analgesic, anti-inflammatory and antipyretic activity. Ibuprofen is used to relieve pain from muscle aches, headache, arthritis, menstrual cramps and dental pain [9-11]. Also, ibuprofen is used to lessen fever. Ibuprofen, nonselectively, blocks the action of cyclooxygenase 1 and 2 enzymes [12,13]. This results in reduced formation of prostaglandins (fever and pain mediators) and thromboxanes (blood clotting stimulators).

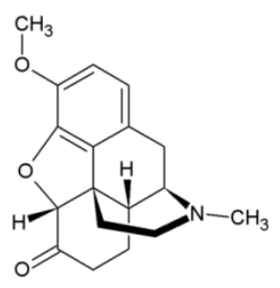

Hydrocodone

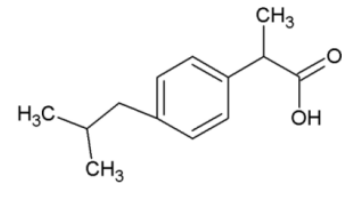

Ibuprofen
Fig. 1: Structures of drugs selected

The hydrocodone and ibuprofen combination is available as a tablet formulation with brand names Vicoprofen (hydrocodone $7.5 \mathrm{mg}$ and ibuprofen $200 \mathrm{mg}$ ), Ibudone (hydrocodone 5/10 $\mathrm{mg}$ and ibuprofen $200 \mathrm{mg}$ ) and Reprexain (hydrocodone 2.5/5/10 mg and ibuprofen $200 \mathrm{mg}$ ). Hydrocodone and ibuprofen combination medication is used to relieve short-term severe pain $[14,15]$. This combination medication works by decreasing molecules which produce fever, pain and inflammation. No analytical technique was found in the literature review to quantify hydrocodone and ibuprofen simultaneously. Therefore, the aim of the current investigation was to develop a novel, rapid, accurate and sensitive stability indicating RP-HPLC method for the analysis of hydrocodone and ibuprofen simultaneously in pure and tablet formulations.

\section{MATERIALS AND METHODS}

\section{Instrumentation}

Chromatographic assay of hydrocodone and ibuprofen was implemented on Waters HPLC Alliance 2695 model with quaternary pump, column thermostat, auto sampler and photodiode array detector (2998 model). Chromatographic data procurement and study were done using the Empower 2.0 version (Waters, USA).

\section{Conditions}

Chromatographic assay was done on a reversed phase Zodiac C18 $(250 \times 4.6 \mathrm{~mm}, 5 \mu \mathrm{m})$ column. The mobile phase, comprising of $0.1 \mathrm{M}$ sodium dihydrogen phosphate ( $\mathrm{pH} 5.0$, tuned with phosphoric acid) and methanol $(60: 40, v: v)$, was filtered via $0.45 \mu \mathrm{m}$ membrane filter, degassed, and delivered with a flow rate of $1.0 \mathrm{ml} / \mathrm{min}$. The sample injection volume and detection wavelength were optimized at $10 \mu \mathrm{l}$ and $234 \mathrm{~nm}$, respectively.

\section{Requirements}

Water for this HPLC assay was made by Millipore water purification system (Millipore, MA, USA). Reference standards of hydrocodone and ibuprofen were procured from Rainbow pharma training labs, Hyderabad, India. Vicoprofen (Abbvie Inc., USA) tablets with label claim $7.5 \mathrm{mg}$ hydrocodone and $200 \mathrm{mg}$ ibuprofen was procured from the provincial pharmacy store. Analytical grade chemicals $\left(\mathrm{NaOH}, \mathrm{HCl}, \mathrm{H}_{2} \mathrm{O}_{2}, \mathrm{NaH}_{2} \mathrm{PO}_{4}\right.$ and phosphoric acid) are from Sd. Fine 
Chemicals Ltd., Mumbai, India. HPLC grade solvent, methanol was obtained from Merck India Ltd, Mumbai, India.

\section{Standard solutions}

Hydrocodone $(7.5 \mathrm{mg}$ ) and ibuprofen $(200 \mathrm{mg})$ reference standards were dissolved in the mobile phase to an ultimate concentration of $75 \mu \mathrm{g} / \mathrm{ml}$ hydrocodone and $2000 \mu \mathrm{g} / \mathrm{ml}$ ibuprofen (stock solution). Calibration solutions at five level concentrations (hydrocodone-3.75, 5.63, 7.5, 9.375, $11.25 \mu \mathrm{g} / \mathrm{ml}$; ibuprofen-100, $150,200,250$ and $300 \mu \mathrm{g} / \mathrm{ml}$ ) were prepared in mobile phase with the above stock solution. Validation solution with a concentration of $7.5 \mu \mathrm{g} / \mathrm{ml}$ hydrocodone and ibuprofen $200 \mu \mathrm{g} / \mathrm{ml}$ was prepared in mobile phase with the above stock solution.

\section{Construction of linearity graph}

To construct linearity graph, 5 distinct concentration solutions (hydrocodone-3.75, 5.63, 7.5, 9.375, $11.25 \mu \mathrm{g} / \mathrm{ml}$; ibuprofen-100, $150,200,250$ and $300 \mu \mathrm{g} / \mathrm{ml}$ ) were prepared. These solutions were analyzed with the outlined HPLC conditions above. Hydrocodone and ibuprofen linearity graphs were made by using the area of peak of drug against corresponding drug concentrations. Regression analyzes were completed with the chromatographic data. The processed linearity graphs and regression equations were then used to quantify the unknown content of hydrocodone and ibuprofen.

Extraction and assay of hydrocodone and ibuprofen combination in tablet

Weigh precisely homogenized tablet sample powder equal to $7.5 \mathrm{mg}$ hydrocodone and $200 \mathrm{mg}$ ibuprofen into a $100 \mathrm{ml}$ standard flask. Added $50 \mathrm{ml}$ of the mobile phase. Sonicated in ultrasonicator for 10 min to extract the drugs completely. Filter the solution using 0.45micrometer membrane filter. Then, the volume was completed to 100 $\mathrm{ml}$ with mobile phase. This is a stock tablet solution with a concentration of $75 \mu \mathrm{g} / \mathrm{ml}$ hydrocodone and $2000 \mu \mathrm{g} / \mathrm{ml}$ ibuprofen. Test tablet solution was made by diluting $1 \mathrm{ml}$ of stock tablet solution to $10 \mathrm{ml}$ using a mobile phase. The final concentration achieved is 7.5 $\mu \mathrm{g} / \mathrm{ml}$ hydrocodone and $200 \mu \mathrm{g} / \mathrm{ml}$ ibuprofen. Injected $10 \mu \mathrm{l}$ of test tablet solution into the HPLC system. Peak areas of hydrocodone and ibuprofen were measured and contents of hydrocodone and ibuprofen in tablet were evaluated via regression equation or linearity graph.

\section{Forced degradation studies}

Stability studies on hydrocodone and ibuprofen stability were conducted to demonstrate how the quality of hydrocodone and ibuprofen varies under the effect of a number of conditions like hydrolysis (with acid, base and water), oxidation (with hydrogen peroxide), temperature and photo [16]. These studies also give information on specific conditions for the storage of drugs [17].

Tablet test solution $(10 \mathrm{ml}, 75 \mu \mathrm{g} / \mathrm{ml}$ hydrocodone and ibuprofen $2000 \mu \mathrm{g} / \mathrm{ml}$ ) was exposed to $0.1 \mathrm{~N}$ hydrochloric acid $(10 \mathrm{ml}), 0.1 \mathrm{~N}$ sodium hydroxide $(10 \mathrm{ml})$, deionized water $(10 \mathrm{ml})$ and $30 \%$ hydrogen peroxide solutions $(10 \mathrm{ml})$ to assess the degree of degradation by acid, base, neutral and oxidation, respectively. Following sonication for $30 \mathrm{~min}$ at $27 \pm 2{ }^{\circ} \mathrm{C}$, degraded samples were completed to $100 \mathrm{ml}$ with the mobile phase (concentration: hydrocodone $7.5 \mu \mathrm{g} / \mathrm{ml}$ and ibuprofen $200 \mu \mathrm{g} / \mathrm{ml}$ ). Samples are filtered with 0.45 micrometer membrane filter after degradation. Injected $10 \mu \mathrm{l}$ of the degraded sample into the HPLC system. Peak areas of hydrocodone and ibuprofen were measured to assess the percent degradation. Tablet sample powder equal to $7.5 \mathrm{mg}$ of hydrocodone and $200 \mathrm{mg}$ of ibuprofen was exposed separately to $105^{\circ} \mathrm{C}$ for $30 \mathrm{~min}$ in hot air oven and to sunlight, for $24 \mathrm{hr}$ to evaluate the extent of thermal and photo degradation, respectively. After exposure, the samples solutions are prepared and analyzed following steps described in section "Extraction and assay of hydrocodone and ibuprofen combination in the tablet". The peaks of hydrocodone and ibuprofen were tested for peak purity in all the degraded samples.

\section{Method validation}

The method's selectivity, linearity, sensitivity, specificity, precision, robustness and accuracy were validated in accordance with ICH rules $[18,19]$.

\section{RESULTS AND DISCUSSION}

During the development of HPLC conditions to assay hydrocodone and ibuprofen simultaneously, different columns (Waters C18, Supelco C18, Thermo, C18 and Zodiac C18) and mobile phases (orthophosphoric acid: methanol, $0.1 \mathrm{M}$ potassium dihydrogen phosphate: methanol, $0.1 \mathrm{M}$ sodium dihydrogen phosphate: methanol) with different ratios were investigated to achieve good separated peak shapes, high sensitivity and apt running time. Hydrocodone and ibuprofen were eluted on Zodiac C18 $(250 \times 4.6$ $\mathrm{mm}, 5 \mu \mathrm{m}$ ) column in an isocratic mode with sodium dihydrogen phosphate $(0.1 \mathrm{M}, \mathrm{pH} 5.0,60 \%)$ and methanol $(40 \%)$ as a mobile phase. The elution time for hydrocodone and ibuprofen was 4.019 min and $4.999 \mathrm{~min}$, respectively. These conditions played a good role in achieving good peak symmetry, less retention time, acceptable resolution and high sensitivity. The maximum intensity of hydrocodone and ibuprofen peaks were observed at $234 \mathrm{~nm}$. Therefore, $234 \mathrm{~nm}$ was chosen as the detection wavelength for quantifying hydrocodone and ibuprofen. The hydrocodone and ibuprofen chromatogram is presented in fig. 2 .

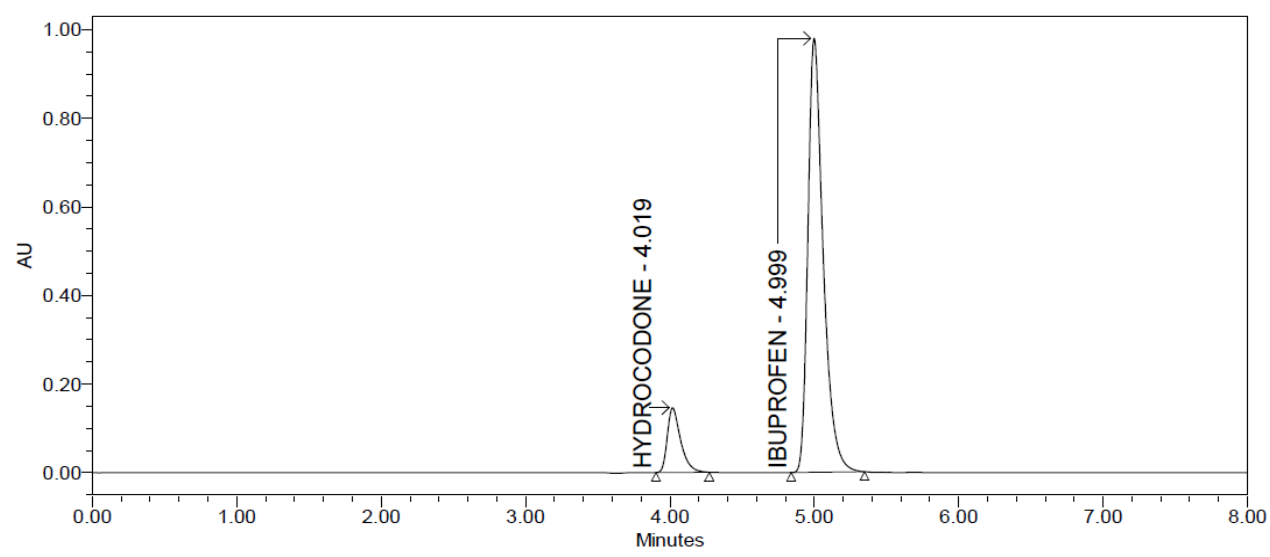

Fig. 2: Optimized chromatogram of hydrocodone and ibuprofen

\section{Method validation}

\section{Selectivity}

During selectivity testing, chromatograms of standard $(7.5 \mu \mathrm{g} / \mathrm{ml}$ hydrocodone and $200 \mu \mathrm{g} / \mathrm{ml}$ ibuprofen), tablet sample $(7.5 \mu \mathrm{g} / \mathrm{ml}$ hydrocodone and $200 \mu \mathrm{g} / \mathrm{ml}$ ibuprofen), blank mobile phase and blank placebo were screened for probable interference. No potential interfering peaks were observed at the retention times of hydrocodone and ibuprofen in the blank mobile phase and placebo chromatograms, hence the method is proved selective (fig. 3 ). 

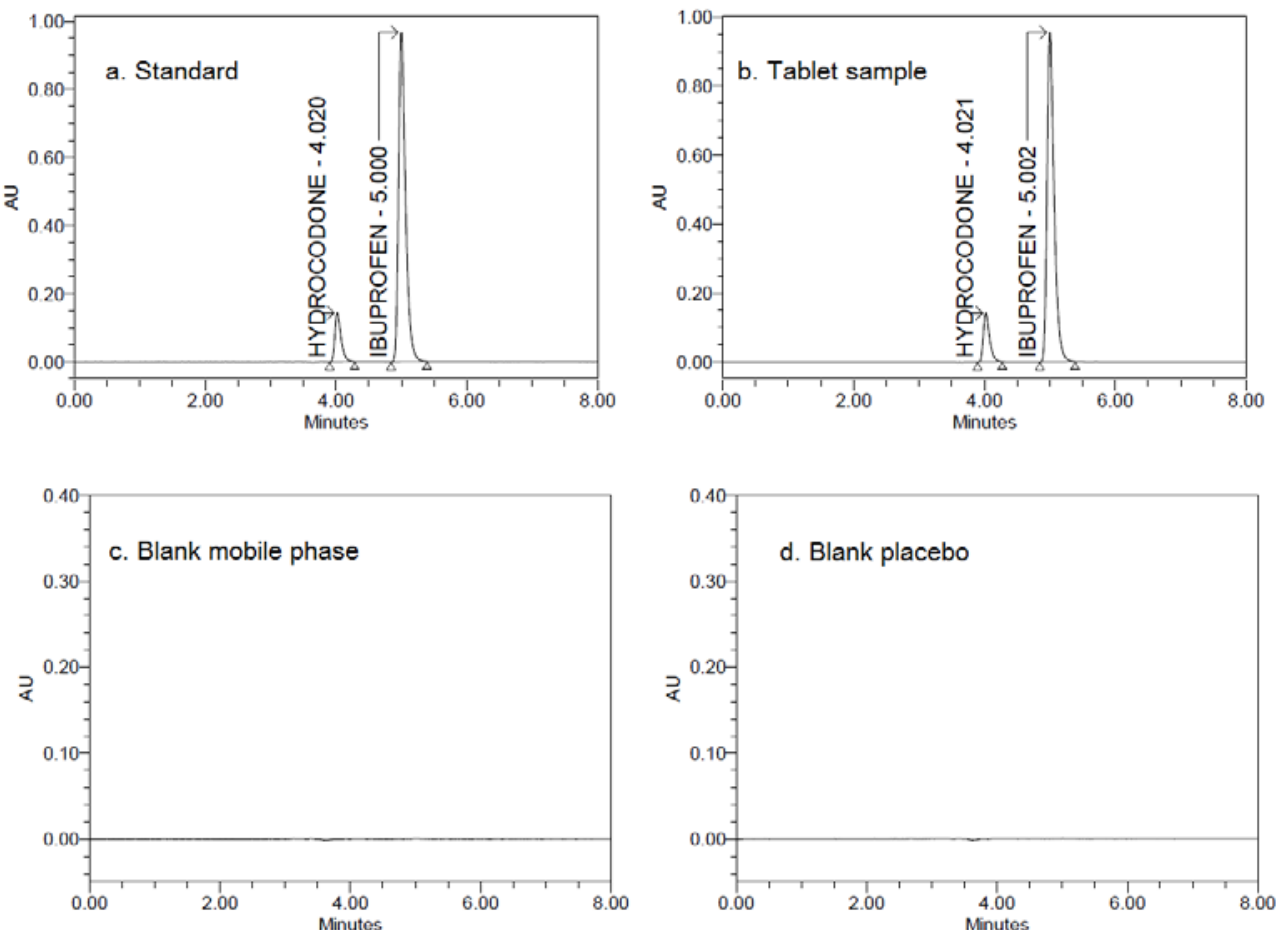

Fig. 3: Chromatograms of (a) standard (b) tablet sample (c) blank mobile phase (d) blank placebo

\section{Linearity and sensitivity}

The linearity curves for hydrocodone ranging from 3.75 to 11.25 $\mu \mathrm{g} / \mathrm{ml}$ and for ibuprofen ranging from 100 to $300 \mu \mathrm{g} / \mathrm{ml}$ were linear and regression coefficients $\left(R^{2}\right)$ are calculated using least square regression analysis. The characteristic linear regression equations are: hydrocodone, $y=12440 \mathrm{x}-1408\left(R^{2}=0.9996\right)$; ibuprofen, $y=$ $35776 \mathrm{x}-2619\left(R^{2}=0.9999\right)$.

Signal to noise ratio criteria of 10 and 3 was used to calculate limit of quantification and limit of detection, respectively. The detection and quantification limits were calculated as $0.048 \mu \mathrm{g} / \mathrm{ml}$ and 0.162 $\mu \mathrm{g} / \mathrm{ml}$ for hydrocodone, $0.192 \mu \mathrm{g} / \mathrm{ml}$ and $0.642 \mu \mathrm{g} / \mathrm{ml}$ for ibuprofen respectively. The values show adequate method sensitivity.

\section{Precision and accuracy}

Accuracy and precision were checked by evaluating five replicates of standard solution $(7.5 \mu \mathrm{g} / \mathrm{ml}$ of hydrocodone and $200 \mu \mathrm{g} / \mathrm{ml}$ of ibuprofen). Precision was described by the percent relative standard deviation while the accuracy was described by the percentage of concentration calculated $[20,21]$. The method was proven to be precise $(\leq 2)$ and accurate (nearer to $100 \%$ ).

Table 1: Summary of precision and accuracy study

\begin{tabular}{lllll}
\hline Drug & $\begin{array}{l}\text { Concentration } \\
(\boldsymbol{\mu g} / \mathbf{m l})\end{array}$ & $\begin{array}{l}\text { Mean peak area } \\
(\mathbf{m A U})^{*}\end{array}$ & $\begin{array}{l}\text { Percent RSD of peak } \\
\text { area* }^{*}\end{array}$ & $\begin{array}{l}\text { Mean concentration } \\
\text { determined }^{*}\end{array}$ \\
\hline Hydrocodone & 7.5 & 929579 & 0.262 & $\begin{array}{l}\text { Mean percentage of } \\
\text { concentration* }^{*}\end{array}$ \\
Ibuprofen & 200 & 7146683 & 0.261 & 198.75 \\
\hline
\end{tabular}

*Mean of six values

\section{Recovery}

Recovery was checked by the standard addition technique. This test was done by fortifying pre-analyzed tablet sample solution with known amounts of hydrocodone $(3.75,7.5$ and $11.25 \mu \mathrm{g} / \mathrm{ml})$ and ibuprofen $(100,200$ and $300 \mu \mathrm{g} / \mathrm{ml})$. Each concentration level was evaluated in triplicate by the proposed method. Good mean recoveries of hydrocodone and ibuprofen at 3 fortified concentration levels indicated the good accuracy of this method and also the absence of hindrance from the tablet excipients (table 2).

Table 2: Summary of recovery study

\begin{tabular}{lllll}
\hline $\begin{array}{l}\text { Level } \\
(\%)\end{array}$ & \multicolumn{2}{l}{ Hydrocodone concentration } & Recovered (\%) & RSD (\%) \\
\cline { 2 - 4 } & Added $(\boldsymbol{\mu g} / \mathbf{m l})$ & Determined $(\boldsymbol{\mu g} / \mathbf{m l})$ & 99.68 & 0.011 \\
100 & 3.75 & 3.74 & 99.63 & 0.025 \\
150 & 7.5 & 7.47 & 99.75 & 0.095 \\
& 11.22 & & 100.49 & 0.068 \\
50 & Ibuprofen concentration & & 100.37 & 0.040 \\
100 & 99.0 & 99.49 & 100.55 & 0.145 \\
150 & 198.0 & 198.73 & 298.64 & \\
\hline
\end{tabular}

*Mean of three values 


\section{System suitability}

System suitability was investigated by five replicate analyses of hydrocodone $(7.5 \mu \mathrm{g} / \mathrm{ml})$ and ibuprofen $(200 \mu \mathrm{g} / \mathrm{ml})$ standard solution. The approval criteria were: $\leq 2 \%$ RSD for peak area and retention time of hydrocodone and ibuprofen; $>2000$ for plate count; $\leq 2$ for peak tailing; $\geq 2$ for resolution. The values obtained are within the approval criteria (table 3 ).

Table 3: System suitability report summary

\begin{tabular}{lll}
\hline Parameter & Hydrocodone & Ibuprofen \\
\hline Precision RSD for peak area* & 0.223 & 0.303 \\
Precision RSD for retention time* & 0.503 & 0.346 \\
Resolution* & - & 5.278 \\
Peak tailing* & 1.486 & 1.436 \\
Plate count* & 9223 & 11028 \\
\hline
\end{tabular}

*Mean of five values

\section{Robustness}

Robustness was investigated through deliberate variations in the $\mathrm{pH}$ of mobile phase ( \pm 0.1 unit), percentage of methanol content $( \pm 5 \%)$, wavelength $( \pm 2 \mathrm{~nm})$, flow rate $( \pm 0.1 \mathrm{ml} / \mathrm{min})$ and column temperature $\left( \pm 2{ }^{\circ} \mathrm{C}\right)$. It was noted that there were no significant changes in peak tailing, resolution and plate count demonstrated that the method developed was robust (table 4).

Table 4: System suitability report summary during the robustness test

\begin{tabular}{|c|c|c|c|c|c|c|}
\hline \multirow[t]{2}{*}{ Value investigated } & \multicolumn{3}{|c|}{ Hydrocodone } & \multicolumn{3}{|l|}{ Ibuprofen } \\
\hline & Plate count & Tailing factor & Resolution & Plate count & Tailing factor & Resolution \\
\hline \multicolumn{7}{|l|}{ Mobile phase pH } \\
\hline Normal & 9223 & 1.48 & - & 11028 & 1.43 & 5.27 \\
\hline-0.1 unit & 9164 & 1.50 & & 10937 & 1.44 & 5.26 \\
\hline+0.1 unit & 9064 & 1.49 & & 10876 & 1.44 & 5.25 \\
\hline \multicolumn{7}{|c|}{ Methanol percentage in the mobile phase } \\
\hline Normal & 9223 & 1.48 & - & 11028 & 1.43 & 5.27 \\
\hline$-5 \%$ & 8517 & 1.44 & & 10301 & 1.40 & 5.17 \\
\hline$+5 \%$ & 9340 & 1.51 & & 11131 & 1.45 & 5.34 \\
\hline \multicolumn{7}{|l|}{ Flow rate } \\
\hline Normal & 9223 & 1.48 & - & 11028 & 1.43 & 5.27 \\
\hline$-0.1 \mathrm{ml} / \mathrm{min}$ & 8517 & 1.44 & & 10301 & 1.40 & 5.17 \\
\hline$+0.1 \mathrm{ml} / \mathrm{min}$ & 8918 & 1.47 & & 10309 & 1.42 & 5.15 \\
\hline \multicolumn{7}{|l|}{ Wave length } \\
\hline Normal & 9223 & 1.48 & - & 11028 & 1.43 & 5.27 \\
\hline$-2 \mathrm{~nm}$ & 9254 & 1.50 & & 11094 & 1.44 & 5.28 \\
\hline$+2 \mathrm{~nm}$ & 9757 & 1.45 & & 11366 & 1.41 & 5.39 \\
\hline \multicolumn{7}{|l|}{ Column temperature } \\
\hline Normal & 9223 & 1.48 & - & 11028 & 1.43 & 5.27 \\
\hline$-2{ }^{\circ} \mathrm{C}$ & 9340 & 1.51 & & 11131 & 1.45 & 5.34 \\
\hline$+2{ }^{\circ} \mathrm{C}$ & 9815 & 1.53 & & 11580 & 1.45 & 5.49 \\
\hline
\end{tabular}

\section{Degradation studies}

After treatment with $0.1 \mathrm{~N} \mathrm{NaOH}$, hydrocodone and ibuprofen showed 2 degradation peaks with retention times of $1.482 \mathrm{~min}$ and $5.825 \mathrm{~min}$. The percent degradation of hydrocodone and ibuprofen were $1.04 \%$ and $15.9 \%$, respectively. Following treatment with $0.1 \mathrm{~N}$ $\mathrm{HCl}$, hydrocodone and ibuprofen showed 5 degradation peaks with retention times of $1.731 \mathrm{~min}, 2.707 \mathrm{~min}, 3.431 \mathrm{~min}, 4.728 \mathrm{~min}, 5.776$ min. The percent degradation of hydrocodone and ibuprofen were $3.28 \%$ and $1.26 \%$, respectively. On hydrolysis with water, hydrocodone and ibuprofen showed 2 degradation peaks with retention times of $3.431 \mathrm{~min}$ and $6.296 \mathrm{~min}$

The percent degradation of hydrocodone and ibuprofen were $0.76 \%$ and $1.97 \%$, respectively. In oxidation condition with hydrogen peroxide, hydrocodone and ibuprofen showed 4 degradation peaks with retention times of $2.186 \mathrm{~min}, 3.330 \mathrm{~min}, 3.440 \mathrm{~min}$ and 5.781 min. The percent degradation of hydrocodone and ibuprofen were $4.59 \%$ and $7.38 \%$, respectively. In dry heat situation, hydrocodone and ibuprofen showed 6 degradation peaks with retention times of $1.458 \mathrm{~min}, 1.617 \mathrm{~min}, 2.655 \mathrm{~min}, 3.420 \mathrm{~min}, 5.821 \mathrm{~min}$ and 6.980 min. The percent degradation of hydrocodone and ibuprofen were $1.25 \%$ and $0.79 \%$, respectively. After degradation with sunlight, hydrocodone and ibuprofen showed 4 degradation peaks with the retention time of $1.654 \mathrm{~min}, 2.124 \mathrm{~min}, 2.588 \mathrm{~min}$ and $3.434 \mathrm{~min}$.
The percent degradation of hydrocodone and ibuprofen were $2.48 \%$ and $0.83 \%$, respectively. The representative chromatograms of hydrocodone and ibuprofen in all degradation conditions are shown in fig. 4.

Peak purity/homogeneity test for hydrocodone and ibuprofen peaks was done to evaluate the interference of degradants at the retention times of hydrocodone and ibuprofen by using photodiode array detection. The results (purity angle is less than purity threshold) indicated that additional peaks were not co-eluting with hydrocodone and ibuprofen peaks (table 5). This demonstrates the ability of the proposed method to assess unequivocally hydrocodone and ibuprofen in the presence of degradants. The assay results of hydrocodone and ibuprofen in all conditions of degradation was summarized in table 5 . All the results proved the stability indicating power and specificity of the developed RP-HPLC method.

Application to the tablet for the analysis of hydrocodone and ibuprofen

The hydrocodone and ibuprofen contents of the tablet samples analyzed are reported in table 6 . The exposed values signify the good accuracy and precision of the method to quantify hydrocodone and ibuprofen simultaneously in tablets. There was no interference from excipients normally found in tablets. 

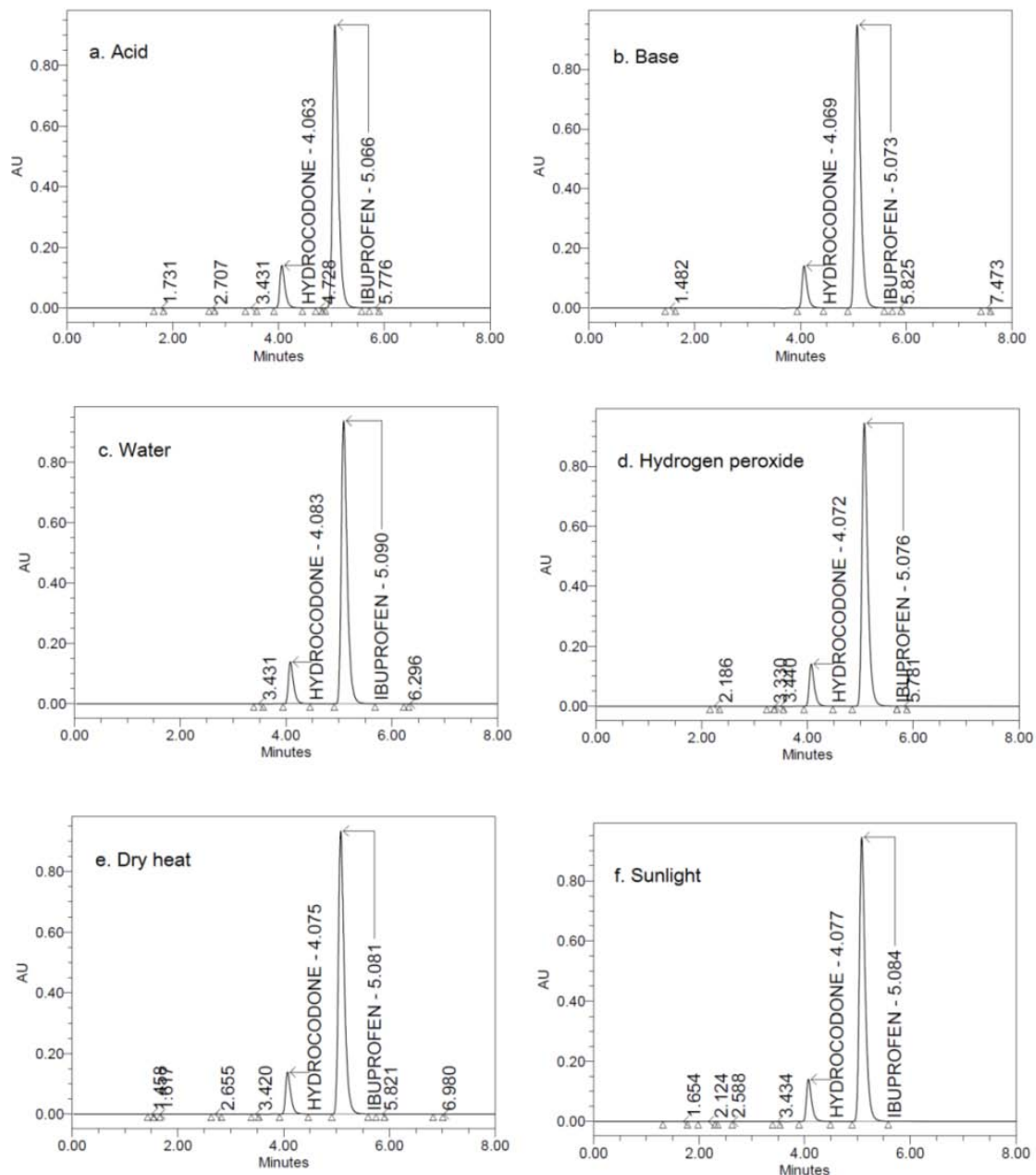

Fig. 4: Chromatograms of hydrocodone and ibuprofen after treatment with (a) Acid (b) Base (c) Water (d) hydrogen peroxide (e) Dry heat (f) Sunlight

Table 5: Summary of peak purity test, and percent assay of hydrocodone and ibuprofen

\begin{tabular}{|c|c|c|c|c|c|c|}
\hline \multirow[t]{2}{*}{ Degradation with } & \multicolumn{3}{|c|}{ Ibuprofen } & \multicolumn{3}{|c|}{ Hydrocodone } \\
\hline & \% Assay & Purity angle & Purity threshold & \% Assay & Purity angle & Purity threshold \\
\hline Acid & 98.74 & 0.715 & 0.748 & 96.72 & 0.338 & 0.453 \\
\hline Base & 84.10 & 0.309 & 0.64 & 98.96 & 0.234 & 0.462 \\
\hline Oxidation & 92.62 & 0.421 & 0.65 & 95.41 & 0.333 & 0.559 \\
\hline Thermal & 99.21 & 0.326 & 0.857 & 98.75 & 0.221 & 0.454 \\
\hline Photo & 99.17 & 0.394 & 0.634 & 97.52 & 0.232 & 0.46 \\
\hline Water & 98.03 & 0.299 & 0.543 & 99.24 & 0.201 & 0.355 \\
\hline
\end{tabular}

Table 6: Assay of hydrocodone and ibuprofen content in dosage form

\begin{tabular}{lllll}
\hline Drug & Labelled claim (mg) & Determined value (mg) & Recovered (\%) & RSD (\%) \\
\hline Hydrocodone & 7.5 & 7.48 & 99.69 & 0.605 \\
Ibuprofen & 200 & 200.94 & 100.47 & 0.912 \\
\hline
\end{tabular}

*Average of three values

\section{CONCLUSION}

A stability indicating RP-HPLC coupled with photodiode array detection method was developed to quantitatively assay hydrocodone and ibuprofen simultaneously in tablets. Validation of the method revealed good linearity, adequate sensitivity, satisfactory selectivity, specificity, accuracy and precision. The developed method is fit for routine use in quality control laboratories and in hydrocodone and ibuprofen stability studies.

\section{ACKNOWLEDGMENT}

The authors are thankful to the management of GITAM University, Visakhapatnam, Andhra Pradesh, India, for providing necessary facilities to carry out the research work.

\section{AUTHOR'S CONTRIBUTION}

This paper is the research work of RKK under the guidance of RS. 


\section{CONFLICTS OF INTERESTS}

No conflicts of interest exist

\section{REFERENCES}

1. Manchikanti L, Atluri S, Kaye AM, Kaye AD. Hydrocodone bitartrate for chronic pain. Drugs Today (Barc) 2015;51:41527.

2. Dhillon S. Hydrocodone bitartrate ER (Hysingla ${ }^{\circledR}$ ER): a review in chronic pain. Clin Drug Investig 2016;36:969-80.

3. Donald CB. Cough suppressant and pharmacologic protussive therapy. ACCP evidence-based clinical practice guidelines. Chest 2006;129(1 Suppl):238S-49S.

4. Hydrocodone, Drugbank. Available from: https:// www.drugbank.ca/drugs/DB00956. [Last accessed on 19 Feb 2019].

5. Hydrocodone, Pubchem. Open chemistry database. Available from: https://pubchem.ncbi.nlm.nih.gov/compound/ hydrocodone. [Last accessed on 19 Feb 2019].

6. Rainsford KD. Ibuprofen: pharmacology, efficacy and safety. Inflammopharmacology 2009;17:275-342.

7. de Martino M, Chiarugi A, Boner A, Montini G, De' Angelis GL. Working towards appropriate use of ibuprofen in children: an evidence-based appraisal. Drugs 2017;77:1295-311.

8. Bushra R, Aslam N. An overview of clinical pharmacology of Ibuprofen. Oman Med J 2010;25:155-66.

9. Ibuprofen, Drugbank. Available from: https://www. drugbank.ca/drugs/DB01050\#reference-L4614. [Last accessed on $22 \mathrm{Feb} 2019]$.

10. Ibuprofen, Pubchem, Open chemistry database. Available from: https://pubchem.ncbi.nlm.nih.gov/compound/ibuprofen\#secti on=Top. [Last accessed on 22 Feb 2019].

11. Kumaresan C. S+ibuprofen (dexibuprofen): the superiornon steroidalantiinflammatory agents for development of pharmaceuticals. Int J Curr Pharm Res 2010;2:1-3.
12. Kim HJ, Lee YH, Im SA, Kim K, Lee CK. Cyclooxygenase inhibitors, aspirin and ibuprofen, inhibit MHC-restricted antigen presentation in dendritic cells. Immune Network 2010;10:92-8.

13. Orlando BJ, Lucido MJ, Malkowski MG. The structure of ibuprofen bound to cyclooxygenase-2. I Struct Biol 2014;189:62-6.

14. Palangio M, Damask MJ, Morris E, Doyle RT Jr, Jiang JG, Landau $\mathrm{CJ}$, et al. Combination hydrocodone and ibuprofen versus combination codeine and acetaminophen for the treatment of chronic pain. Clin Ther 2000;22:879-92.

15. Palangio M, Wideman GL, Keffer M, Landau CJ, Morris E, Doyle RT Jr, et al. Combination hydrocodone and ibuprofen versus combination oxycodone and acetaminophen in the treatment of postoperative obstetric or gynecologic pain. Clin Ther 2000;22:600-12.

16. International Conference on Harmonization, Stability testing of new drug substances and products (Q1AR2), in Proceedings of the International Conference on Harmonization, Geneva, Switzerland; 2003.

17. Mistry V, Mishra R. Simultaneous estimation, validation, and forced degradation studies of betahistine dihydrochloride and domperidone in a pharmaceutical dosage form using RP-HPLC method. Asian J Pharm Clin Res 2018:11:125-9.

18. International Conference on Harmonization of Technical Requirements for Registration of Pharmaceuticals for Human Use, ICH Harmonized Tripartite Guideline. Validation of Analytical Procedures: Text and Methodology Q2(R1), ICH, Geneva, Switzerland; 2005.

19. Sharma S, Goyal S, Chauhan K. A review on analytical method development and validation. Int J Appl Pharm 2018;10:8-15.

20. Hemant KJ, Umakant SJ. Development and validation of RPHPLC method for estimation of darunavir ethanolate in bulk and tablets. Int J Pharm Pharm Sci 2015;7:386-9.

21. Ravichandran V, Shalini S, Sundaram KM, Rajak H. Validation of analytical methods-strategies and importance. Int J Pharm Pharm Sci 2010;2:18-22. 